Delft University of Technology

\title{
Mesoporous Silica Formation Mechanisms Probed Using Combined Spin-Echo Modulated Small-Angle Neutron Scattering (SEMSANS) and Small-Angle Neutron Scattering (SANS)
}

Schmitt, Julien; Zeeuw, Jan Joost; Zeeuw, Jan Joost; Plomp, Jeroen; Bouwman, Wim G.; Washington, Adam L.; Duif, Chris P.; Thijs, Michel A.; Parnell, Steven R.; More Authors

DOI

10.1021/acsami.0c03287

\section{Publication date}

2020

Document Version

Final published version

Published in

ACS Applied Materials and Interfaces

\section{Citation (APA)}

Schmitt, J., Zeeuw, J. J., Zeeuw, J. J., Plomp, J., Bouwman, W. G., Washington, A. L., Duif, C. P., Thijs, M. A., Parnell, S. R., \& More Authors (2020). Mesoporous Silica Formation Mechanisms Probed Using Combined Spin-Echo Modulated Small-Angle Neutron Scattering (SEMSANS) and Small-Angle Neutron Scattering (SANS). ACS Applied Materials and Interfaces, 12(25), 28461-28473. https://doi.org/10.1021/acsami.0c03287

Important note

To cite this publication, please use the final published version (if applicable).

Please check the document version above. 
Green Open Access added to TU Delft Institutional Repository 'You share, we take care!' - Taverne project

\section{https://www.openaccess.nl/en/you-share-we-take-care}

Otherwise as indicated in the copyright section: the publisher is the copyright holder of this work and the author uses the Dutch legislation to make this work public. 


\section{Mesoporous Silica Formation Mechanisms Probed Using Combined Spin-Echo Modulated Small-Angle Neutron Scattering (SEMSANS) and Small-Angle Neutron Scattering (SANS)}

Julien Schmitt,* Jan Joost Zeeuw, Jeroen Plomp, Wim G. Bouwman, Adam L. Washington, Robert M. Dalgliesh, Chris P. Duif, Michel A. Thijs, Fankang Li, Roger Pynn, Steven R. Parnell, and Karen J. Edler

Cite This: ACS Appl. Mater. Interfaces 2020, 12, 28461-28473

Read Online

ABSTRACT: The initial formation stages of surfactant-templated silica thin films which grow at the air-water interface were studied using combined spin-echo modulated small-angle neutron scattering (SEMSANS) and small-angle neutron scattering (SANS). The films are formed from either a cationic surfactant or nonionic surfactant $\left(\mathrm{C}_{16} \mathrm{EO}_{8}\right)$ in a dilute acidic solution by the addition of tetramethoxysilane. Previous work has suggested a two stage formation mechanism with mesostructured particle formation in the bulk solution driving film formation at the solution surface. From the SEMSANS data, it is possible to pinpoint accurately the time associated with the formation of large particles

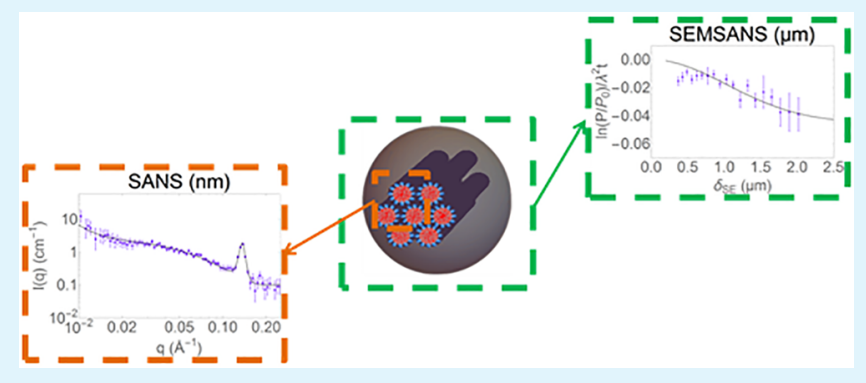
in solution that go on to form the film and to show their emergence is concomitant with the appearance of Bragg peaks in the SANS pattern, associated with the two-dimensional hexagonal order. The combination of SANS and SEMSANS allows a complete depiction of the steps of the synthesis that occur in the subphase.

KEYWORDS: small-angle neutron scattering (SANS), spin-echo modulated small-angle neutron scattering (SEMSANS), mesoporous silica, kinetics, micelles, mesophase, particles, silica films

\section{INTRODUCTION}

Mesoporous materials, discovered in $1992,{ }^{1}$ present a welldefined and organized porosity. They are formed by mixing an amphiphilic structuring agent with an inorganic precursor in solution. Depending on the synthesis conditions, the material is synthesized as submicrometric grains in solution, ${ }^{2,3}$ monoliths, ${ }^{4,5}$ or as thin-films, either via spin-coating, ${ }^{6}$ dipcoating, ${ }^{7,8}$ or by spontaneous formation at the air-water interface. $^{9}$

Ever since the groups of Ozin ${ }^{10}$ and Aksay ${ }^{11}$ reported on the synthesis of mesophase inorganic thin films formed at the solution surface in 1996, these materials have been a topic of great interest. The ability to manipulate the mesostructure in the films, their intrinsic porosity, the size of their pores, and other morphological parameters give the films potential applications in a wide variety of scientific and technological fields such as selective membranes, ${ }^{12}$ catalysis, ${ }^{13,14}$ gas sensors, ${ }^{15}$ and drug-delivery. ${ }^{16}$ Extensive research has been done on these self-assembling silica-surfactant systems; however, the mechanism of this self-assembly, leading to the formation of the mesostructured thin films, is still a matter of debate. Currently, the two possible mechanisms that have been proposed in the literature are the silica-coated micelles mechanism and the silica-droplet phase separation mechanism. ${ }^{9}$ The former relies on the addition of silica species to the corona of the micelles in the solution, influencing the micelles shape, usually promoting more elongated packing parameters. Then, either some of the silica-enriched micelles migrate to the interface to form the film, or alternatively form mesostructured particles in the subphase that later migrate to the interface. The latter mechanism suggests the rapid formation of phaseseparated droplets rich in surfactant and silica species, often called flocs, and possibly remaining quasi globular micelles in the bulk. The flocs are suggested as nucleation sites for micelle elongation and reorganization into a mesostructure. In the first case, the signal of elongating micelles should be measured in the bulk before the signal of larger flocs, while the second hypothesis suggests the appearance of large objects in the bulk prior to any reshaping of the micelles.

Received: February 20, 2020

Accepted: April 24, 2020

Published: April 24, 2020 
To investigate the behavior of the micelles and particles in the bulk, a combination of traditional small-angle neutron scattering (SANS) and spin-echo modulated small-angle neutron-scattering (SEMSANS) ${ }^{17-19}$ was implemented on the LARMOR instrument (ISIS, Rutherford Appleton Laboratory, U.K.). This allowed for the investigation of phenomena on the nano- and micrometer scale simultaneously, providing valuable insights on the behavior of the micelles prior to and during aggregation. Furthermore, it enables the identification of the formation of an ordered mesostructure within the larger aggregates. Finally, when evidence was found for the phase-separation mechanism, SANS/SEMSANS was used to determine whether the micelles aggregated in an orderly fashion, or whether random aggregation was followed by ordering into the later observed mesostructure. Because this was the first-ever application of this combined technique on a real physical-chemical system, a description of the setup is provided below.

\section{MATERIAL AND METHODS}

Films Preparation. Mesoporous silica film forming solutions were prepared following already established protocols. ${ }^{20,2 \mathrm{P}}$ The films are formed from solution by mixing tetramethoxysilane (TMOS) with a surfactant solution in acidic conditions. The surfactant (SF) used was either hexadecyltrimethylammonium bromide (CTAB) or octaethylene glycol monohexadecyl ether $\left(\mathrm{C}_{16} \mathrm{EO}_{8}\right)$ depending on the synthesis. The $\mathrm{C}_{16} \mathrm{EO}_{8}$ was purchased from Nikko Chemicals, Japan (BC- 8SY). CTAB, $\mathrm{HCl}, \mathrm{D}_{2} \mathrm{O}$, and TMOS were purchased from Sigma-Aldrich and all were used as received. For each synthesis, the molar ratio SF: $\mathrm{HCl}: \mathrm{D}_{2} \mathrm{O}$ was 1:2.39:658, in agreement with previous studies. ${ }^{9}$ Several syntheses were studied by varying the molar ratio between the silica source and the surfactant. In detail, three molar ratios $r_{\mathrm{mol}}=\frac{n_{\mathrm{TMOS}}}{n_{\mathrm{SE}}}=3.6,7.21$, and 10.81 were investigated, using $\mathrm{CTAB}$ as the surfactant, and one ratio $\left(r_{\text {mol }}=7.21\right)$ for $\mathrm{C}_{16} \mathrm{EO}_{8}$. Those ratios correspond to ratios previously investigated with other techniques. ${ }^{9}$ TMOS was added to the already prepared surfactant solution in $0.2 \mathrm{M} \mathrm{HCl}$, which was then stirred for $1 \mathrm{~min}$ before filling the SANS cell. The cell cap was left off to allow evaporation and hence have similar synthesis conditions to previous studies.

Combined SEMSANS and SANS Measurements. In a typical SANS measurement, the sample loaded in a cell is exposed to a wellcollimated neutron beam, inducing scattering. The intensity of the scattered beam $I$ is recorded on a pixelated detector, while the nonscattered, direct, beam is discarded using a beamstop. The scattered intensity is azimuthally averaged and given as a function of the scattering vector $q=\frac{4 \pi}{\lambda} \sin \left(\frac{\theta}{2}\right)$, where $\lambda$ is the wavelength of the neutron beam and $\theta$ is the scattering angle. The $q$-range accessible in SANS permits probing dimensions typically ranging from 1 to a few hundred nm.

To access the larger micrometer-scale structures at very low $q$, we have to measure the scattering which is contained within the footprint of the direct beam, which is usually discarded. However, with the addition of several components we can gain additional information using a new technique called SEMSANS, proposed by Gähler. ${ }^{22} \mathrm{We}$ implemented this method using a polarized beam and two superconducting Wollaston prisms ${ }^{23,24}$ to create a spatial modulation of the intensity of the neutron beam at the detector position. The change in modulation amplitude caused by scattering from the sample gives the sample density autocorrelation function $G\left(\delta_{\mathrm{SE}}\right)^{17-19}$ where $\delta_{\mathrm{SE}}$, the spin-echo length, is the length scale being probed and is dependent upon the period $(p)$ of the neutron intensity modulation at the detector. The quantity $G\left(\delta_{\mathrm{SE}}\right)$ is the same as that measured in spin-echo small-angle neutron scattering (SESANS) ${ }^{25}$ and we can use the same models and transforms to interpret the data. Unlike SESANS, the SEMSANS method has all the components for neutron spin manipulation before the sample and hence can be combined with the SANS technique for simultaneous measurements. Because of the use of time-of-flight, a range of wavelengths is probed at the same time, allowing the measurement of SEMSANS and SANS simultaneously.

A detailed description of the different components of the setup for the SEMSANS measurements and of the procedure for the data corrections can be found in refs 26-31 and in the Supporting Information.

The measurements were performed on the LARMOR instrument at the ISIS Pulsed Neutron and Muon Source. The sample to detector distance is $4 \mathrm{~m}$ and the accessible SANS $q$-range is $0.008-0.4 \AA^{-1}$, while the accessible range of spin-echo lengths was $0.35<\delta_{\mathrm{SE}} \leq 2.5$ $\mu \mathrm{m}$. A series of runs were performed every 19 min until an equilibrium state was found.

SESANS. In addition to the combined SEMSANS/SANS measurements, we also utilized the monochromatic SESANS instrument at the TU-Delft. ${ }^{32}$ Briefly, this utilizes a $2.03 \AA$ beam with a series of inclined magnetized films to encode the polarization. This instrument has encoding films before and after the sample and cannot be combined with SANS. However, this is able to reach significantly higher spinecho lengths. For these measurements the same correlation function $G\left(\delta_{\mathrm{SE}}\right)$ is determined. Nonetheless, measurement at each spin-echo length has to be performed separately (due to the monochromatic nature of the beam) and the sample was measured for 11 different spin-echo lengths which were cycled through every 19 min (i.e., 100 s measurement per spin-echo length). This was to preserve a similar time structure to the combined SEMSANS/SANS measurements made on LARMOR.

\section{SANS AND SEMSANS/SESANS DATA ANALYSIS}

SANS Data Treatment. The theoretical model for the formation of mesostructured materials studied in small-angle scattering has already been described in the literature. ${ }^{33,34}$ The expression for the intensity can be described as the sum of four terms

$$
I_{\text {tot }}(q)=I_{\text {micelles }}(q)+I_{\text {Bragg }}(q)+I_{\text {Porod }}(q)+\text { bg }
$$

where $I_{\text {micelles }}(q)$ is the contribution of the ellipsoidal micelles of surfactant in solution; $I_{\mathrm{Bragg}}(q)$ is the contribution of the forming mesostructured material; $I_{\text {Porod }}(q)$ is a Porod term at the very low angles associated with the forming particles, and bg is a constant background term.

For ellipsoidal micelles with radii $(R, R, \varepsilon R), I_{\text {micelles }}(q)$ (in $\mathrm{cm}^{-1}$ ) can be expressed as ${ }^{35}$

$$
I_{\text {micelles }}(q)=A P(q, R, \varepsilon, \sigma)
$$

where $A=n\left(\rho_{\text {micelles }}-\rho_{0}\right)^{2}$ is the scale factor, depending on the number of micelles per unit volume $n$ (in $\mathrm{cm}^{-3}$ ), $\rho_{\text {micelles }}$ and $\rho_{0}$ are the scattering length densities of the core of the micelles and solvent, respectively $\left(\rho_{0}=6.335 \times 10^{10} \mathrm{~cm}^{-2}\right.$ for $\left.\mathrm{D}_{2} \mathrm{O}\right)$, and $P(q)$ is the form factor of the micelles with their volume included (in $\left.\mathrm{cm}^{6}\right) . P(q)$ is defined as

$$
P(q, R, \varepsilon, \sigma)=\left\langle\int_{0}^{\pi / 2}[F(q, r(R, \varepsilon, \theta))]^{2} \sin \theta \mathrm{d} \theta\right\rangle_{\sigma}
$$

where $r(R, \varepsilon, \theta)=R\left(\sin ^{2} \theta+\varepsilon^{2} \cos ^{2} \theta\right)^{1 / 2}$, to describe the ellipticity of the radii.

$$
F(q, r)=V(r) f_{s}(q, r)
$$

is the form factor amplitude for a sphere of core radius $r$. $V(r)=\frac{4}{3} \pi r^{3}$ is the volume of a sphere of radius $r$ and 

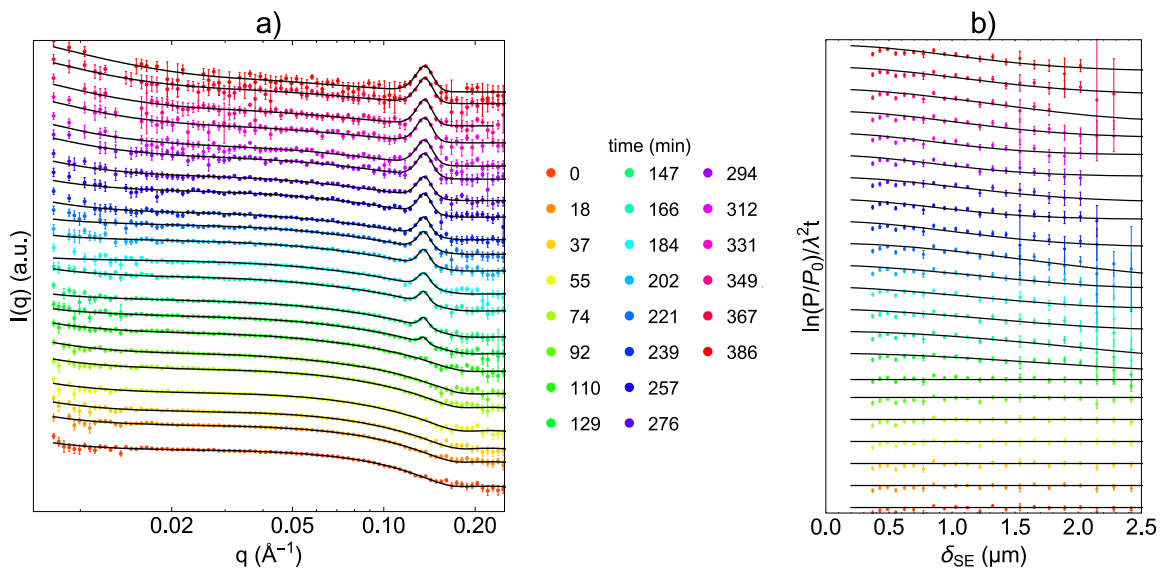

Figure 1. (a) $I(q)$ versus $q\left(\right.$ in $\left.\AA^{-1}\right)$ obtained from SANS measurements and (b) normalized neutron spin-echo signal $\frac{\ln \left(\frac{P}{P_{0}}\right)}{\lambda^{2} t}$ versus the spin-echo length $\delta_{\mathrm{SE}}$ (in $\mu \mathrm{m}$ ) obtained from SEMSANS measurements for the kinetics using CTAB as surfactant with $r_{\text {mol }}=3.6$. All patterns $(\mathrm{a}, \mathrm{b})$ have been shifted for clarity (nonshifted patterns can be found in Figure S1, SI). The color gives the time associated with each pattern. In black lines, fits of the SANS and SEMSANS data are presented according to the models given in SANS and SEMSANS Data Analysis.

$f_{s}(q, r)=\frac{3[\sin (q r)-q R \cos (q r)]}{(q r)^{3}}$ is the normalized form factor amplitude of a sphere of radius $r$.

Finally, the polydispersity in size $\langle.\rangle_{\sigma}$ is taken into account using the Schulz-Zimm distribution, that is, for a certain function $F^{\prime}(q, r)$

$$
\left\langle F^{\prime}(q, r)\right\rangle_{\sigma}=\int f_{\mathrm{SZ}}\left(R, r, \frac{1}{\sigma^{2}}-1\right) F^{\prime}(q, R) \mathrm{d} R
$$

where $f_{\mathrm{SZ}}\left(x, x_{0}, z\right)=\frac{x^{z}}{\Gamma(z+1)}\left(\frac{z+1}{x_{0}}\right)^{z+1} e^{-(z+1) x / x_{0}}$. In order to easily compare the contribution from the free micelles to the overall intensity, one can rewrite eq 2 as follows

$$
I_{\text {micelles }}(q)=I_{\text {micelles }}(q=0) P^{\prime}(q, R, \varepsilon, \sigma)
$$

where

$$
\begin{aligned}
& I_{\text {micelles }}(q=0)=A P(0, R, \varepsilon, \sigma)=n\left(\rho_{\text {micelles }}-\rho_{0}\right)^{2} P(0, R, \varepsilon, \sigma) \\
& \quad=n\left(\rho_{\text {micelles }}-\rho_{0}\right)^{2} V_{\text {ell }}^{2}(R, \varepsilon)
\end{aligned}
$$

is the intensity from the micelles at $q=0$ (in $\mathrm{cm}^{-1}$ ) and $P^{\prime}(q, R, \varepsilon, \sigma)=\frac{P(q, R, \varepsilon, \sigma)}{P(0, R, \varepsilon, \sigma)}$ is the normalized form factor. $V_{\text {ell }}(R, \varepsilon)=\frac{4}{3} \pi \varepsilon R^{3}$ is the volume in $\mathrm{cm}^{3}$ of an ellipsoid of radius $(R, R, \varepsilon R)$.

We note that previous studies, using different $\mathrm{D}_{2} \mathrm{O} / \mathrm{H}_{2} \mathrm{O}$ contrasts, showed that the micelles are of a core-shell type. ${ }^{36}$ Nonetheless, in our case with only one contrast we can fit the scattering from the micelles using only this homogeneous ellipsoid form factor.

The contribution associated with the mesophase is given by $I_{\text {Bragg }}(q)^{37,38}$

$$
I_{\text {Bragg }}(q)=\sum_{h k l} I_{h k l} L_{h k l}(q, a, D, \nu)
$$

where $L_{h k l}(q, a, D, \nu)$ is the function that will reproduce the lattice organization (e.g., Bragg peaks found at the positions $q_{h k l}$ ), taking into account the lattice parameter $a$ (in $\mathrm{nm}$ ) associated with the peak position and type of organization, the lattice dimension $D$ (in $\mathrm{nm}$ ) which depends on the peak width, the numerical parameter $\nu$ that is associated with the peak shape ( 0 for a Lorentzian shape, 1 for a Gaussian shape), and $h, k, l$ which are the Miller indices of the reticular planes associated with the mesophase. Values of the $h, k, l$ indices and hence the peaks positions will be highly dependent on the type of mesophase studied. In the $q$-range used in this study, only the first peak can be measured, which prevents discrimination of which type of mesophase is forming (2D hexagonal, cubic, and so forth) and hence extraction of the lattice parameter $a$.

Nonetheless, for the CTAB templated films we can assume that the Bragg peak for the particles formed in the subphase is associated with a 2D-hexagonal ordering, as already wellestablished in the literature ${ }^{36,39,40}$ and measuring one peak is enough to extract both the lattice parameter and lattice dimension. Indeed, for a 2D-hexagonal mesophase the position of the Bragg peaks is given by the formula $q_{h k l}=q_{h k}=\frac{4 \pi}{a \sqrt{3}} \sqrt{h^{2}+k^{2}+h k}$. The first peak is that case associated with the (10) plane and is found at position $q_{10}=\frac{4 \pi}{a \sqrt{3}}$. The intensity parameter of this peak $I_{10}$ can be written as

$$
I_{10}=I\left(q=q_{10}\right)=n^{\prime}\left(\rho_{\text {micelles }}-\rho_{0}^{\prime}\right)^{2} P\left(q_{10}, R, \varepsilon, \sigma\right)
$$

It is associated not only with the number of micelles within the mesostructured phase domains $n^{\prime}$ but also the contrast between the micelles and the silica walls $\left(\left(\rho_{\text {micelles }}-\rho^{\prime}{ }_{0}\right)^{2}\right.$, where $\rho_{0}^{\prime}$ is the scattering length density of the condensing "silica walls" between the micelles). As only one Bragg peak was extracted, it is not possible to separate the two parameters $n^{\prime}$ and $\rho^{\prime}{ }_{0}$.

The films templated with $\mathrm{C}_{16} \mathrm{EO}_{8}$ form a variety of mesophases dependent on the silica/surfactant molar ratio. At the ratio studied here, $r_{\text {mol }}=7.2$, the films contain a $P m \overline{3} n$ cubic phase, ${ }^{21}$ however the structure within the particles in the subphase cannot be determined from the single peak observed here, although, as for the CTAB templated particles, it can still be used to extract a $d$-spacing and domain size.

Finally, we note that the width of the peak is also limited by the resolution in $q$ (called $\Delta q$ ) of the SANS detector. This means the domain size of the mesophase can be accurately extracted only for values $D \leq \frac{2 \pi}{\Delta q}$. 
At small angles, the Porod term $I_{\text {Porod }}(q)$ is associated with the growing mesophase with a parameter related to the smooth interface of the forming mesostructured particles

$$
I_{\text {Porod }}(q)=\frac{K}{q^{4}}
$$

The $q$-range used in SANS does not allow extraction of the size of the particles, which is instead observed using the spin-echo configuration.

SEMSANS and SESANS Data Treatment. For both SEMSANS and SESANS, data are expressed in the form of $\left(G\left(\delta_{\mathrm{SE}}\right)-1\right) * \Sigma_{t}=\frac{\ln \left(\frac{P}{P_{0}}\right)}{\lambda^{2} t}$ as a function of spin-echo length $\left(\delta_{\mathrm{SE}}\right)$, where $\lambda$ is the neutron wavelength, $t$ is the sample thickness and $\Sigma_{t}$ is a measure of the scattering power. In SEMSANS, $P=P(\lambda)$ is the amplitude of the intensity modulations on the detector for the sample at a given wavelength, $P_{0}$ is the one from the empty beam, while in SESANS they are the amplitude of the polarization directly. A more detailed explanation of the extraction of $\frac{\ln \left(\frac{P}{P_{0}}\right)}{\lambda^{2} t}$ versus $\delta_{\mathrm{SE}}$ is given in SI and in ref 41.

Both the SESANS and SEMSANS data were fitted to a simple dilute sphere model as given by Andersson et al. ${ }^{25}$ This is characterized by two parameters: a measure of the scattering power independent from wavelength and sample thickness $\left(\Sigma_{t}\right)$ and radius $\left(R_{\text {particles }}\right.$ in $\left.\mu \mathrm{m}\right)$. We note that for concentration of particles below about $10 \%$

$$
\Sigma_{t}=\frac{3}{2} R_{\text {particles }}(\Delta \rho)^{2} \varphi(1-\varphi)
$$

where $\Delta \rho$ is the contrast between the particles and the solvent and $\varphi$ is the volume fraction of particles. This means that $\Sigma_{t}$

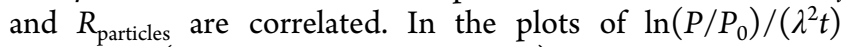
versus $\delta_{\mathrm{SE}}$ (see for example Figure $1 \mathrm{~b}$ ), the signal decreases until it reaches a plateau. The position in $\delta_{\mathrm{SE}}$ of the plateau can be related to $2 R_{\text {particles, }}$, while the value of $\ln \left(P / P_{0}\right) /\left(\lambda^{2} t\right)$ at the plateau is related to $\Sigma_{t}$. In SEMSANS, we can only probe a limited spatial range of spin-echo lengths $\delta_{\mathrm{SE}}(\leq 2.5 \mu \mathrm{m})$, which means we will have an accurate measurement of $R_{\text {particles }}$ and $\Sigma_{t}$ only for particles $\leq 2.5 \mu \mathrm{m}$, where the plateau of the signal is clearly observed. This is nonetheless sufficient to evidence the formation of micrometer-sized particles in this study.

\section{RESULTS}

Synthesis Using CTAB at the Ratio $r_{\text {mol }}=3.6$. A synthesis solution made using $\mathrm{CTAB}$ as surfactant with a molar ratio $r_{\text {mol }}=3.6$ was investigated using the combined SEMSANS and SANS setup with SANS and SEMSANS patterns as a function of time given in Figure 1. This ratio has the lowest amount of silica of the three investigated and hence presents a slower speed of reaction. Both the SANS and the SEMSANS data were fitted using the models for mesostructured 2Dhexagonal domain growth kinetics and for growth of spherical particles, respectively, detailed in SANS and SEMSANS Data Analysis. SANS patterns (Figure 1a) demonstrate that at the beginning of the reaction $\mathrm{CTAB}$ micelles in solution are present with a slightly prolate shape. Over time, an elongation of the micelles is observed, before a Bragg peak arises at around $2 \mathrm{~h}$ (observed but too weak to be fitted at $110 \mathrm{~min}$, labeled below as $\left.t_{\mathrm{Bragg}}\right)$, associated with the formation of a hybrid 2D-hexagonal mesostructure, which further grows in intensity with time. Concomitantly to the Bragg peak's initial appearance, the SEMSANS signal diverges from a flat line (Figure 1b, divergence is present at $110 \mathrm{~min}$ but clearer at 129 min) with a modulation observed around $\delta_{\mathrm{SE}}=1.5 \mu \mathrm{m}$, characteristic of particles typically bigger than $1 \mu \mathrm{m}$ in solution.

A detailed analysis of the parameters extracted from fitting the SANS and SEMSANS data for the entire reaction is given in Figures 2 and 3.

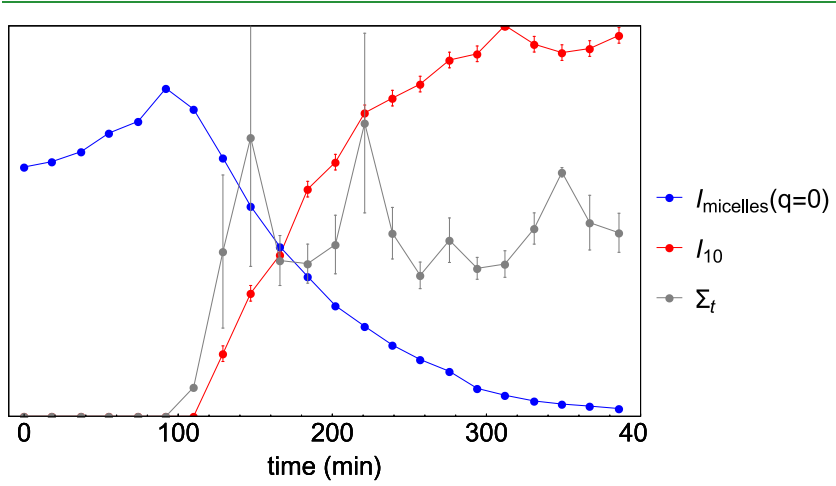

Figure 2. Comparison over time of the different contributions to the SANS and SEMSANS signals during the reaction in solution using $\mathrm{CTAB}$ at a ratio $r_{\text {mol }}=3.6$ : (blue) the intensity $I_{\text {micelles }}(q=0)$ of $\mathrm{CTAB}$ micelles in solution extracted from the fitting of the SANS data, (gray) the scattering power $\Sigma_{t}$ of micrometer-sized particles measured in SEMSANS, and (red) the intensity $I_{10}$ of the Bragg peak observed in SANS. Different scales in $y$ have been overlapped to allow a clear depiction of the variation of these parameters with time. Figure S2 in SI gives separate graphs of these three parameters with their associated scales.

Figure 2 allows a clear comparison with time between $I_{\text {micelles }}$ $(q=0)$, the intensity from the micelles of CTAB in solution, $I_{10}$, the peak intensity associated with the mesophase organization, and $\Sigma_{t}$ the scattering power associated with the micrometer-sized particles observed in SEMSANS. The signal associated with the micelles first increases until $t_{\mathrm{Bragg}}=110 \mathrm{~min}$ before strongly decreasing while signals for both mesostructure and micrometer-sized particles increase after $t_{\text {Bragg. The first }}$ increase of $I_{\text {micelles }}(q=0)$ is assumed to be due to the incorporation of silica species into the CTAB micelles, modifying both the micelle shape and their contrast with the solvent as further described in the next paragraph. The decrease after the emergence of the Bragg peak is explained by the continuing consumption of the micelles to form the mesophase. On the other hand, signals associated with the 2Dhexagonal phase and the micrometer-sized particles appear around the same time (although $I_{10}$ was too weak to be fitted at $110 \mathrm{~min}$ ). $\Sigma_{t}$ shows a sharp increase before fluctuating around a plateau, which seems to indicate that large particles are quickly formed and then their number remains roughly constant with time. Comparatively, the signal of $I_{10}$ grows more slowly with time, mirroring the decrease of the signal of micelles of $\mathrm{CTAB}$ in solution.

A more detailed analysis can be obtained through the study of the parameters extracted from the fits and given in Figure 3. This allows a sketch of the different steps of the reactions to be proposed, shown in Scheme 1.

The shape of micelles clearly evolves during the reaction, as seen from the values of the micelle radius $R$ and the micelle ellipticity $\varepsilon$ with time (Figure $3 \mathrm{a}, \mathrm{b}$ ). At $t=0$, micelles of CTAB 
a)

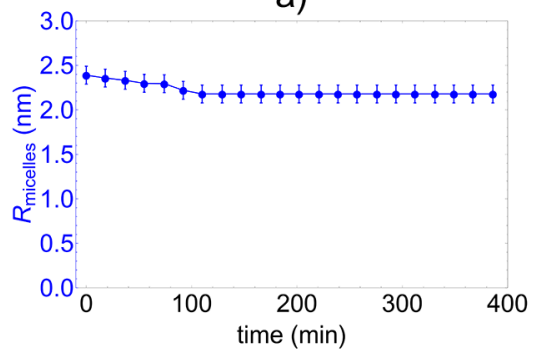

c)

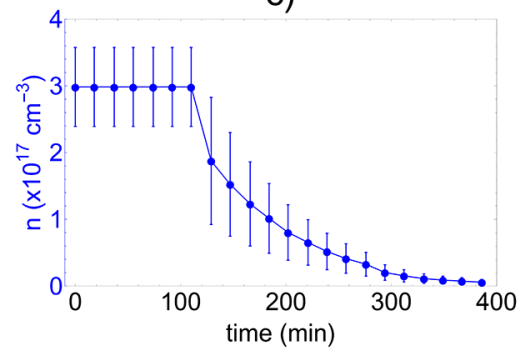

e)

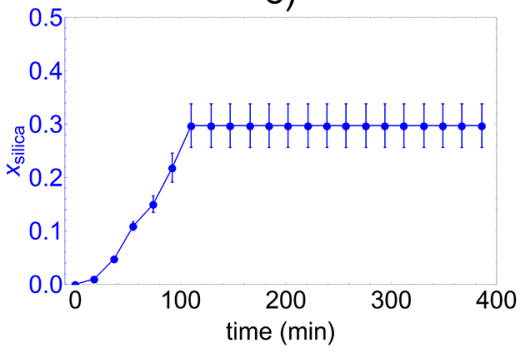

g)

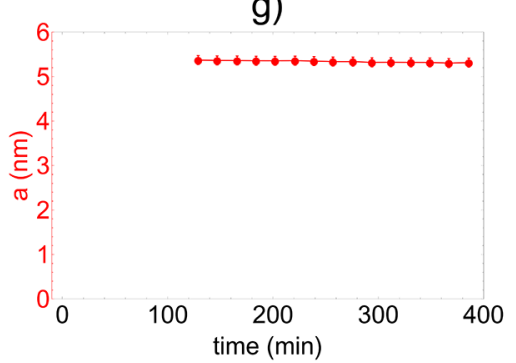

b)

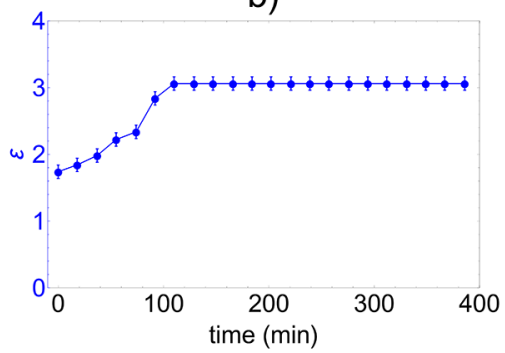

d)

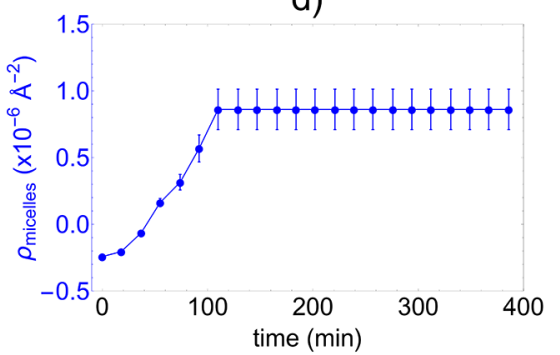

f)

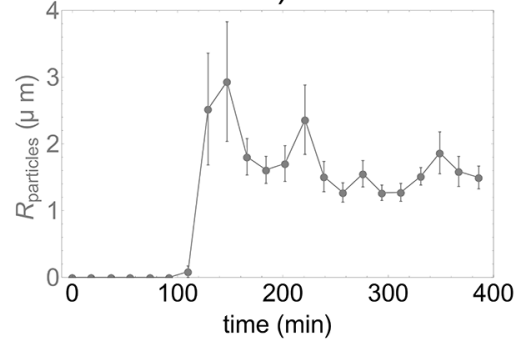

h)

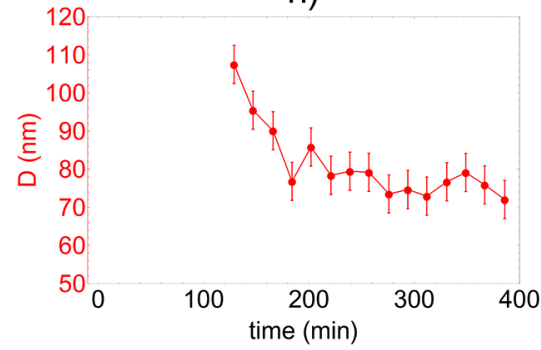

Figure 3. Evolution of different parameters extracted from fitting the SANS and SEMSANS data from the reaction in solution using CTAB at a ratio $r_{\text {mol }}=3.6$. (Blue) parameters associated with the micelles of CTAB in solution: (a) the micelle radius $R_{\text {micelles }}(\mathrm{nm})$, (b) the ellipticity of the micelles $\varepsilon$. From $I_{\text {micelles }}(q=0)\left(\mathrm{cm}^{-1}\right)$ plotted in Figure 2, (c) the number of micelles per unit volume $n\left(\mathrm{~cm}^{-3}\right)$ and $(\mathrm{d})$ the scattering length density of the micelles $\rho_{\text {micelles }}\left(\AA^{-2}\right)$ were extracted, assuming that before the Bragg peaks appearance $n$ stays constant, while once the mesophase is forming, it is $\rho_{\text {micelles }}$ which does not change. (e) The proportion of silica within the micelles $x_{\text {silica }}$ is extracted by $\rho_{\text {micelles }}=x_{\text {silica }} \rho_{\text {silica }}+(1-$ $\left.x_{\text {silica }}\right) \rho_{\text {СТAB }}$ (Gray) (f) the radius $R_{\text {particles }}(\mu \mathrm{m})$ of micrometer-sized particles detected in SEMSANS. (Red) parameters associated with the 2Dhexagonal organization within the micrometer-sized particles from fitting of the SANS Bragg peak: $(\mathrm{g})$ the lattice parameter of the 2D-hexagonal order $a(\mathrm{~nm})$ and $(\mathrm{h})$ the domain size $D(\mathrm{~nm})$.

can be fitted using a model of slightly prolate ellipsoids $(R=$ $2.4 \pm 0.1 \mathrm{~nm}$ and $\varepsilon=1.8 \pm 0.1$ ) in solution (step 1 in Scheme $1)$. With time, changes in the SANS pattern can be reproduced well by an elongation of the micelles $(R=2.2 \pm 0.1 \mathrm{~nm}$ and $\varepsilon$ $=3.0 \pm 0.1$ at $\left.t=t_{\mathrm{Bragg}}\right)$, (step 2 in Scheme 1$)$. After $t_{\mathrm{Bragg}}$, the contribution of the micelles in the SANS pattern is modeled only by decreasing $I_{\text {micelles }}(q=0)$ without further modification of the micelles form factor ( $R$ and $\varepsilon$ fixed). This elongation can be explained by the incorporation of silica species in the micelles. Indeed, from $I_{\text {micelles }}(q=0)$ we can extract the number of micelles per unit volume $n$ and the scattering length density of the micelles $\rho_{\text {micelles }}$ (Figure $3 \mathrm{c}, \mathrm{d}$ ). Before precipitation $\left(t<t_{\mathrm{Bragg}}\right)$, we make the hypothesis that the number of micelles remains roughly constant in solution, assuming the change in shape can be mostly related to the addition of silica in their corona (although it is possible that reshaping of the micelles would induce a change in aggregation number and probably a slight decrease of $n$, neglected here). We can hence extract $\rho_{\text {micelles }}$ that is found to increase from $-0.242 \times 10^{-6} \AA^{-2}$ at time $t=0$ (scattering length density of CTAB) to $0.9 \times 10^{-6} \AA^{-2}$ once the Bragg peak is detected. From $\rho_{\text {micelles, }}$ it is also possible to derive the amount of silica species $x_{\text {silica }}$ in the micelles (Figure 3e), assuming micelles are composed only of CTAB and silica. This amount is found to reach almost $30 \%$ before the mesophase precipitation. As only a core model is needed to fit the data, it is impossible to 
Scheme 1. Sketch of the Different Steps Proposed to Be Involved in the Formation of a Mesostructured Film ${ }^{a}$

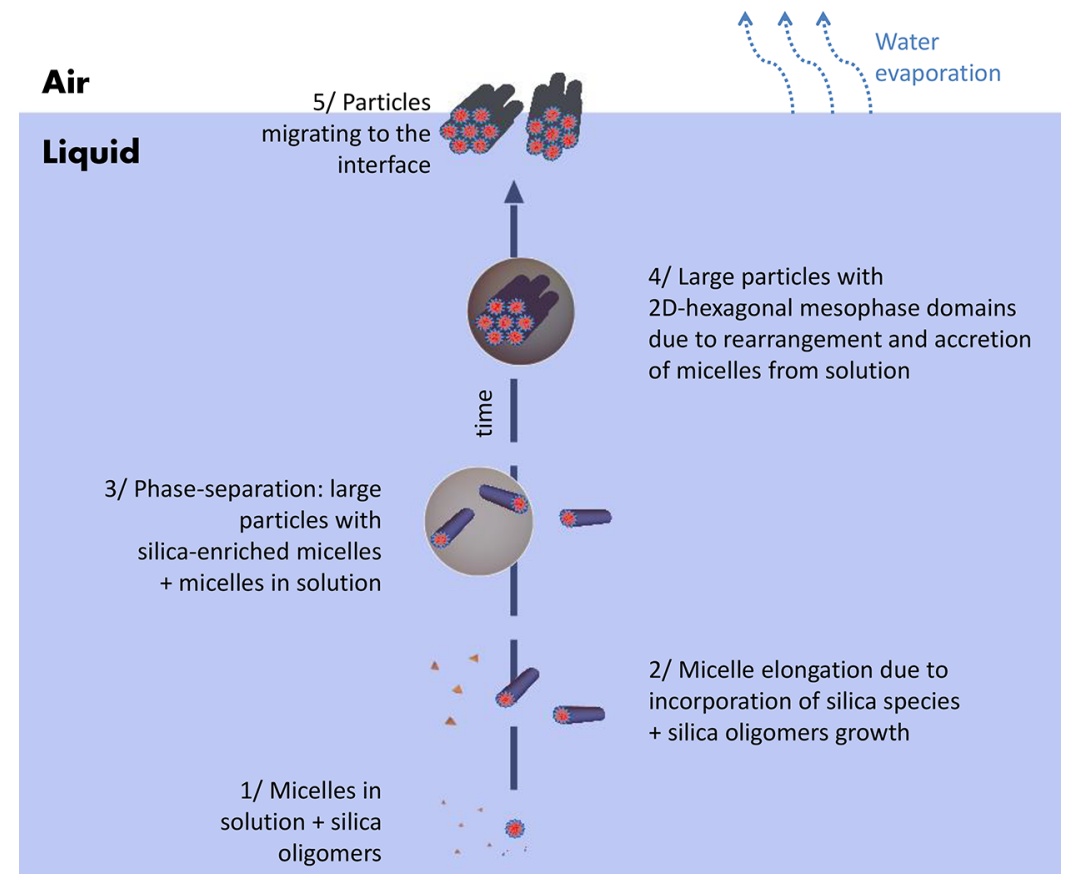

${ }^{a}$ In the reaction using $\mathrm{CTAB}$ as surfactant at a silica:surfactant molar ratio $r_{\text {mol }}=3.6$.

describe with accuracy the localization of the silica species in the micelles. Moreover, it is possible that a fraction of $\mathrm{D}_{2} \mathrm{O}$ is present in the micelles, neglected here, leading to a probable overestimation of $x_{\text {silica }}$. After $t_{\mathrm{Bragg}}$, as the shape of the micelles does not evolve, $\rho_{\text {micelles }}$ is fixed while the decrease of $I_{\text {micelles }}(q$ $=0$ ) can be well described by the decrease of the number of micelles in solution $n$, consistent with their consumption by the particles to form the 2D-hexagonal network. The fact that this parameter equals zero after a long time is proof that most of the micelles are eventually consumed to form the mesophase (steps 3 and 4 in Scheme 1).

As seen in Figure 2, at $t=t_{\text {Bragg }}$ a signal of micrometer-sized particles is detected in SEMSANS, concomitant with a Bragg peak of a mesophase in SANS.

The radius of the large particles $R_{\text {particles }}$ quickly reaches a very large size (at $t=t_{\mathrm{Bragg}}=110 \mathrm{~min}$, fits give a $R_{\text {particles }}$ at about $80 \mathrm{~nm}$, while it is found above $2 \mu \mathrm{m}$ for the next measurement made at $129 \mathrm{~min}$ ). Then, it slightly decreases with time, again with some fluctuations, reaching $1.5 \pm 0.2 \mu \mathrm{m}$ at $386 \mathrm{~min}$ (Figure 3f). As for the 2D-hexagonal organization, the lattice parameter $a$ does not vary significantly with time, whereas the apparent decrease in the domain size $D$ observed around $t_{\text {Bragg }}$ is probably explained by an overestimation of $D$ at those early stages due to the weak Bragg peak intensity at this time (Figure $3 \mathrm{~g}, \mathrm{~h}$ ). A value of $D$ of approximately $80 \mathrm{~nm}$ is found throughout the entire kinetics series, which is more than 10 times smaller than the particle radius observed in SEMSANS. This measurement of domain size may be artificially limited by the resolution of the SANS detector, however an earlier measurement on film growth using X-ray reflectivity where peak width was not defined by the detector resolution suggested a domain size around $200 \mathrm{~nm} .{ }^{39}$ This size is still much smaller than the particle sizes observed here, which may suggest that the $1.5 \mu \mathrm{m}$ particles are composed of several 2D-hexagonal domains.
As described previously, after $t=t_{\mathrm{Bragg}}$, we observed the following three phenomena: the appearance of particles in the SEMSANS signal, the appearance and slow growth of the Bragg peak associated with the $2 \mathrm{D}$-hexagonal mesophase, and the slow decrease of the signal from micelles in solution. The concomitance between these phenomena is a direct indication that the nucleation of the particles is due to the rapid aggregation of silica-enriched micelles into phase separated particles. This immediately triggers a $2 \mathrm{D}$-hexagonal organization of the micelles within the particles, due to the higher concentration and interactions between micelles. Interestingly, while $\Sigma_{t}$ quickly reaches a plateau around about $t=160 \mathrm{~min}$, indicating that most phase-separated particles are formed at that time (step 3 in Scheme 1), both $I_{\text {micelles }}(q=0)$ and $I_{10}$ continue to evolve with time, which suggests that the micelle organization continues for a long period after particle formation, by the formation of new 2D-hexagonal domains in the particles, as the domain size does not increase with time (step 4 in Scheme 1). Around $160 \mathrm{~min}$ where most particles are formed, the number of micelles which are not organized is about half of the initial number of micelles. These unorganized micelles could be either already present in the particles (hence at a relatively high concentration) or still free in solution (in a dilute regime). As the signal of unorganized micelles is always fitted as noninteracting, it is assumed that most are still in solution. This other half of unorganized micelles is consumed over time, mirroring the growth of the Bragg peak intensity $I_{10}$, suggesting that the increase of number of 2D-hexagonal domains in the particles is probably not only due to the micelles' reorganization within the particles but also to further adsorption of more silica-enriched micelles from the water phase. Adsorption of surfactant-silica composite micelles onto silica surfaces in an epitaxial fashion is well-established, ${ }^{11,42}$ and once the particle surface exists it is highly likely that further accretion of micelles onto this surface will continually occur. Possibly, the decrease in size of the large particles arises due to 

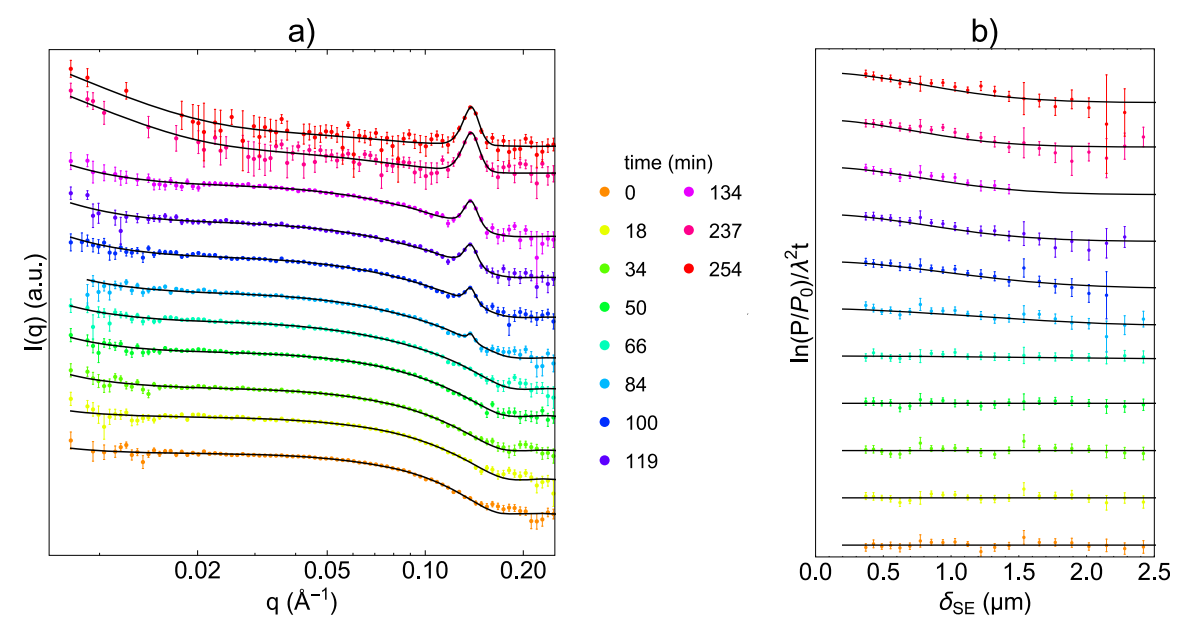

Figure 4. (a) $I(q)$ versus $q$ (in $\AA^{-1}$ ) obtained from SANS measurements and (b) normalized neutron spin-echo signal $\frac{\ln \left(\frac{P}{P_{0}}\right)}{\lambda^{2} t}$ versus the spin-echo length $\delta_{\mathrm{SE}}$ (in $\left.\mu \mathrm{m}\right)$ obtained from SEMSANS measurements for the kinetic runs using CTAB as surfactant with $r_{\mathrm{mol}}=7.21$. All patterns $(\mathrm{a}, \mathrm{b})$ have been shifted for clarity (nonshifted patterns can be found in Figure S3, SI). The color gives the time associated with each pattern. In black lines, fits of the SANS and SEMSANS data are presented according to the models given in SANS and SEMSANS Data Analysis.

the continuing silica condensation and reorganization of both silica and micelles in the particles, leading to compaction of initial aggregates which are composed of several different $\sim 80$ $\mathrm{nm}$ domains of $2 \mathrm{D}$ hexagonal organization.

Finally, after $t=160 \mathrm{~min}$ the polydispersity in the size of the large particles is quite narrow, especially considering the fact that they are probably composed of several domains as already seen by the difference between the domain size and the particles radius. This reflects the formation process which is reminiscent of a phase separation, similar to coacervation observed in polymer-surfactant systems where uniform liquid droplets form at a critical composition. ${ }^{43}$ A coacervation-like mechanism has previously been suggested for the formation of micelle-templated silica particles formed in bulk solution in systems where no film formation occurs. ${ }^{44}$

The mesostructured silica film at this silica/surfactant ratio is hence obtained by later migration of a portion of the $2 \mathrm{D}$ hexagonal ordered particles to the interface (step 5 in Scheme 1).

Increasing the Amount of TMOS (CTAB, $r_{\mathrm{mol}}=7.21$ and 10.81). Two other syntheses using $C T A B$ as surfactant were carried at higher TMOS concentrations $\left(r_{\mathrm{mol}}=7.21\right.$ and 10.81 in Figures 4 and 5, respectively, and also in SI S3, S4, and S5). Similar stages to the kinetics were also observed when $r_{\text {mol }}=7.21$ compared to the already discussed $r_{\text {mol }}=3.6$ (SANS and SEMSANS data are given in Figure 4). Nonetheless, observation of micrometer-scaled particles is observed at an earlier time for $r_{\text {mol }}=7.21$ (already at $66 \mathrm{~min}$, compared to 110 min for $r_{\text {mol }}=3.6$ ), see Figure 6 and Figure S6, SI. A smaller particle radius is also found at approximately $1.1 \mu \mathrm{m}$ whereas the lattice parameter and domain size are similar to the case $r_{\mathrm{mol}}=3.6$ (see Figure S7, SI). The fact that precipitation occurs sooner at $r_{\mathrm{mol}}=7.21$ is expected as more silica species are present. ${ }^{20}$ Also, this fastest precipitation is associated with micelles less enriched with silica $\left(x_{\text {silica }}\right.$ around $15 \%$, compared to $30 \%$ ) and less anisotropic (at the precipitation time, $\varepsilon=2.5$ \pm 0.1 for $r_{\text {mol }}=7.21$, compared to $3.0 \pm 0.1$ for $r_{\text {mol }}=3.6$, see Figures 3 and 6 ). This suggests that the precipitation time is driven by the silica polymer size rather than the micelle properties, similar to the effects of polymer molecular weight on coacervation observed in polymer surfactant systems. In such systems, a threshold molecular weight must be achieved before phase separation into droplets occurs, ${ }^{43}$ and here as silica concentration increases this molecular weight will be reached more rapidly.

For the molar ratio $r_{\text {mol }}=10.81$, a loss of the beam prevented us from measuring the beginning of the kinetic run (see SANS and SEMSANS measurements in Figures S4 and S5, SI). Although a signal from SEMSANS shows the presence of about $1-2 \mu \mathrm{m}$ particles once the beam was restored (first pattern at 164 min, see Figure S4), no Bragg peak can be seen in the highly noisy SANS patterns, in correspondence with earlier SANS studies on solutions at this ratio. ${ }^{36}$ Hence, to have a better understanding of the mechanisms involved in that reaction, we performed additional SESANS experiments at Delft and compared them to a set of data previously measured using SANS on LOQ. ${ }^{36}$ SESANS and SANS data are given in Figure 5. The most striking aspect is that in this case, even if $\mathrm{CTAB}$ micelles are very slowly elongating with time (see fitting parameters given in Figure 7), no Bragg peak is observed. Moreover, at long times (around $650 \mathrm{~min}$ in SANS and 800 min in SESANS) a sudden change in the signal is observed in SANS and a signal of very large particles (about $8 \mu \mathrm{m}$ ) is detected in SESANS. The modification of the SANS signal gives a sharp increase of both the scaling factor and the ellipticity of the micelles (see Figure 7) but it is believed this is an artifact due to the growth of those large objects measured in SESANS. Indeed, the fits obtained at those times cannot reproduce accurately the data with the emergence of a "shoulder" around $0.1 \AA^{-1}$. This shoulder, associated with the increase of the signal at small angles $\left(q<0.05 \AA^{-1}\right)$, could be the signature of the formation of disordered fractal-like silica gel particles, possibly from further aggregation of the 1-2 $\mu \mathrm{m}$ particles observed in SEMSANS at earlier times. We note that below $300 \mathrm{~min}$, the CTAB micelles in this system are still only slightly prolate with an ellipticity $<1.5$ (see Figure 7 ). This would indicate that if the phase-separation is triggered by the silica polymer size, the rearrangement into a mesophase is controlled by the micelle properties and most importantly its silica loading. Associated with the absence of Bragg peaks, 
a)

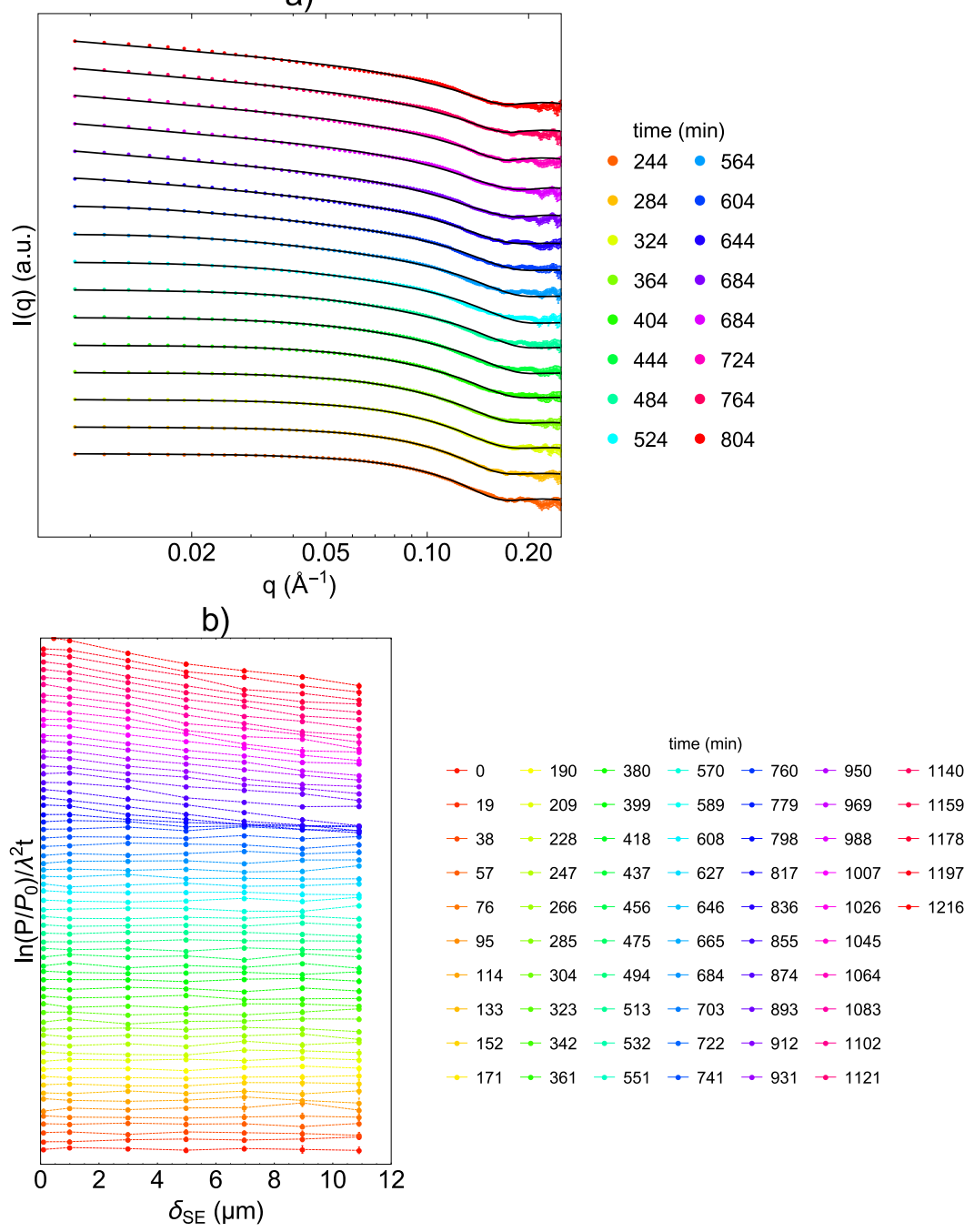

Figure 5. (a) $I(q)$ versus $q$ (in $\AA^{-1}$ ) obtained from previous SANS measurements (on LOQ ${ }^{36}$ and (b) normalized neutron spin-echo polarization $\frac{\ln \left(\frac{P}{P_{0}}\right)}{\lambda^{2} t}$ versus the spin-echo length $\delta_{\mathrm{SE}}($ in $\mu \mathrm{m})$ obtained from SESANS measurements at Delft for the kinetic runs using CTAB as surfactant with $r_{\mathrm{mol}}=10.80$. Fits of the SANS data are provided in black lines.

these results indicate that for this ratio, a silica polymer network is forming in solution almost independently of the $\mathrm{CTAB}$ micelles, associated with the high amount of silica species in the solution, favoring silica-silica over silica-CTAB interactions. This silica network does collapse into particles rather than forming a solution spanning gel, trapping the micelles, but at this point the silica polymer is too condensed to allow rearrangement into the ordered $2 \mathrm{D}$ hexagonal phase within the particles. The difference in times between the changes observed in SANS (650 $\mathrm{min}$ ) and SESANS (800 $\mathrm{min}$ ) is not necessarily significant as small variations in reproducing the same synthesis (e.g., slight changes in $\mathrm{pH}$ or level of deuteration) might influence the times associated with each event in the kinetics.

These results are a strong indication that the mechanisms of the film formation are profoundly modified at this ratio. Interestingly, at $r_{\text {mol }}=10.80$, the film forms much more slowly and has a much smoother interface compared to $r_{\text {mol }}=3.6$ and 7.21 , when CTAB is used as surfactant. ${ }^{20}$ The difference of roughness of the film has been previously explained by suggesting that for $r_{\mathrm{mol}}=10.81$, it was formed by the aggregation of individual micelles at the interface, whereas for the other ratios the film is formed by already formed 2Dhexagonal particles migrating to the interface. This scenario is consistent with the results obtained in this study, especially the absence of mesostructured particles at $r_{\text {mol }}=10.81$. It is possible that the high amount of silica species creates a competition between adsorption of silica species onto the micelles and silica-silica condensation, preventing the organization of the elongated micelles into a 2D-hexagonal order within particles in the bulk. The elongated micelles will hence more slowly migrate to the interface to form a smooth silica film with a $2 \mathrm{D}$-hexagonal organization to allow the highest packing between the micelles. On the contrary, for the two other ratios the rapid formation of mesostructured silica particles in the subphase consumed the hybrid micelles, as seen by the decrease of the number of micelles per unit volume $n$, and the film is formed by accumulation of these submicrometer grains at the interface. The small amount of mesostructured grains involved in the film formation compared to the ones present in the subphase prevents the quantification of this phenomenon. 
a)

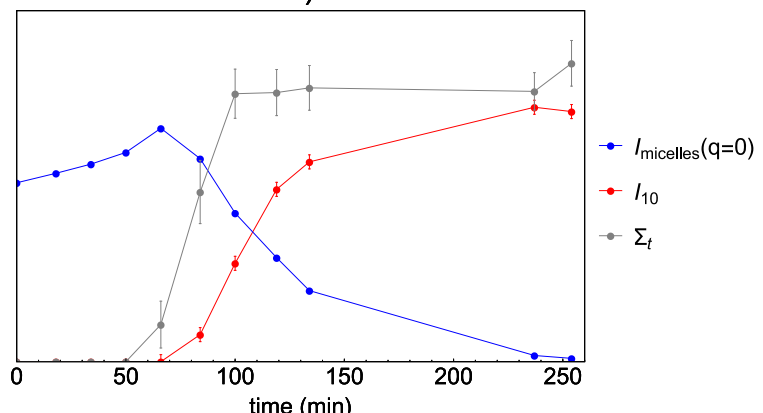

b)
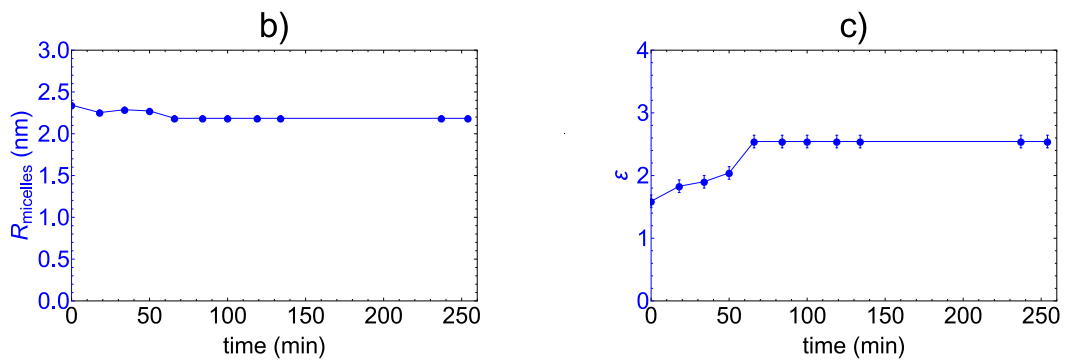

d)

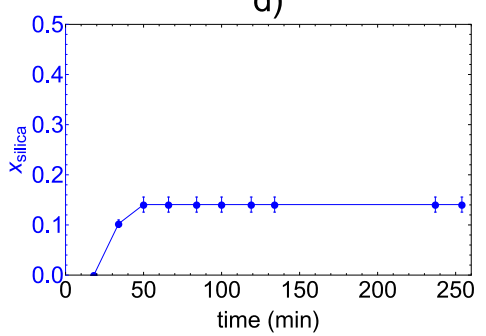

e)

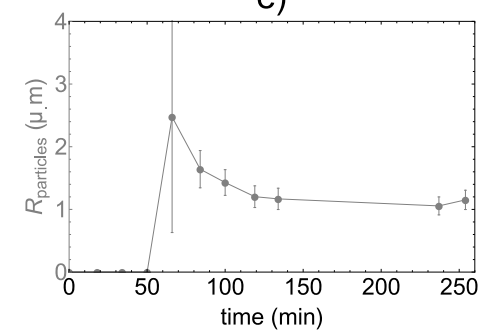

Figure 6. Evolution of different parameters extracted from fitting the SANS and SEMSANS data of the reaction in solution using CTAB at a ratio $r_{\text {mol }}=7.21$. (a) Comparison between $I_{\text {micelles }}(q=0)$ (blue), $I_{10}$ (red), and $\Sigma_{t}$ (gray) with time. Separated graphs with their associated scales can be found in Figure S6, SI. (Blue) (b) the micelle radius $R_{\text {micelles }}(\mathrm{nm})$, (c) the ellipticity of the micelles $\varepsilon$, and (d) $x_{\text {silica }}$ the amount of silica incorporated in the micelles obtained from fitting the SANS data. (Gray) (e) the radius $R_{\text {particles }}(\mu \mathrm{m}$ ) of $\mu \mathrm{m}$-sized particles detected in SEMSANS. Other fitting parameters can be found in Figure S7, SI.

Comparison with a Synthesis Made Using $\mathrm{C}_{16} \mathrm{EO}_{8}$ at $r_{\text {mol }}=7.21$. A final synthesis was studied replacing CTAB by $\mathrm{C}_{16} \mathrm{EO}_{8}$ at a molar ratio $r_{\text {mol }}=7.21$ (Figure 8). Before the addition of TMOS, $\mathrm{C}_{16} \mathrm{EO}_{8}$ micelles can be well modeled by a purely spherical model with a radius $R=3.2 \pm 0.1 \mathrm{~nm}$. However, similar to the synthesis with $\mathrm{CTAB}$, an elongation of the micelles is observed in solution with time (until $t=110$ min) with the micelle radius decreasing from 3.2 to $2.5 \mathrm{~nm}$ while the ellipticity $\varepsilon$ increases from 1 to 4.8 (see parameters in Figure 9). $\mathrm{C}_{16} \mathrm{EO}_{8}$ micelles experience more drastic changes in their morphology during the synthesis than $\mathrm{CTAB}$ at the same ratio, which is expected due to the larger headgroup that will interact with the silica species (eight EO groups compared to $\left.\mathrm{N}\left(\mathrm{CH}_{3}\right)_{3}^{+}\right)$. This results in a higher proportion of silica within the micelles (above 50\% compared to $15 \%$ for $\mathrm{CTAB}$ at the same ratio) and an overall slower kinetics compared to CTAB at this silica/surfactant ratio.

At time $t=110 \mathrm{~min}$, a Bragg peak arises that is associated with the precipitation of the mesostructure in the subphase, once again concomitant with the appearance of a signal from particles in SEMSANS (see parameters in Figure 9). The same events as previously observed with $\mathrm{CTAB}$ can be pinpointed with this system even if $2 \mu \mathrm{m}$-sized particles and ordered mesophase are still forming at the last recorded pattern (239 $\mathrm{min})$, evidencing a slower evolution than for $\mathrm{CTAB}$ at the same ratio.
As only one Bragg peak is observed, questions about the type of mesostructure formed in the particles arise. The peak is found at position $q=0.110 \pm 0.005 \AA^{-1}$ which gives a $d$ spacing $d=5.7 \pm 0.2 \mathrm{~nm}$. Previous studies of films made in these synthesis conditions showed a $P m \overline{3} n$ cubic mesophase in the films but with a $d$-spacing expected at $6.3 \mathrm{~nm}^{21} \mathrm{~A} d$ spacing of $5.7 \mathrm{~nm}$ was found for $\mathrm{C}_{16} \mathrm{EO}_{8}$ mesostructured films at a ratio $r_{\mathrm{mol}}=3.6$ and associated with a $2 \mathrm{D}$-hexagonal mesophase.

The results demonstrate that the formation of micelletemplated silica particles $\mathrm{CTAB}$ and $\mathrm{C}_{16} \mathrm{EO}_{8}$ follows the same steps, characterized by an elongation of the micelles due to the incorporation of silica species, before phase separation and formation of the mesostructure, observed simultaneously in SANS and SEMSANS. It is expected for $r_{\text {mol }}=3.6$ and 7.21 that these particles slowly migrate to the interface to form the film, as previously suggested. ${ }^{20,21,39}$

\section{CONCLUSION}

Using a combination of SEMSANS and SANS, the kinetics of formation of mesoporous films were studied. Specifically the method allows measurement of the evolution of the system within the subphase over a wide range of length scales, in contrast to GISAXS or reflectivity that focus on the air-water interface. It was observed that for these syntheses, micelles of surfactant are initially present within the subphase. Evolution 
a)

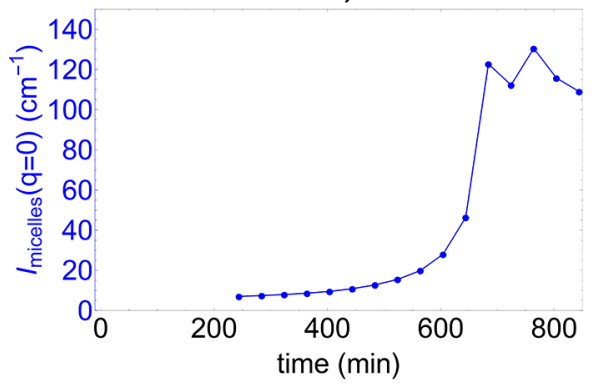

c)

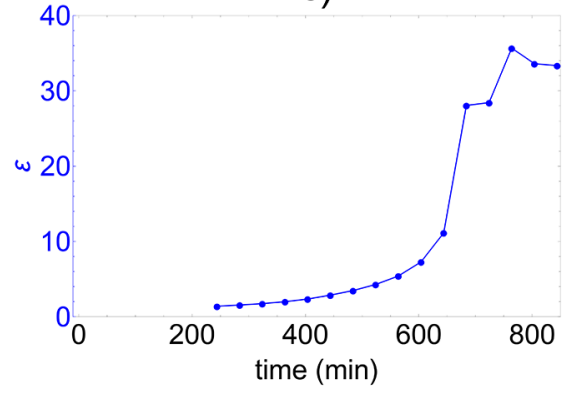

b)

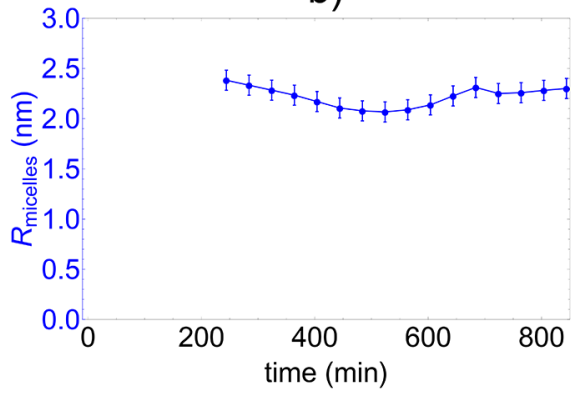

d)

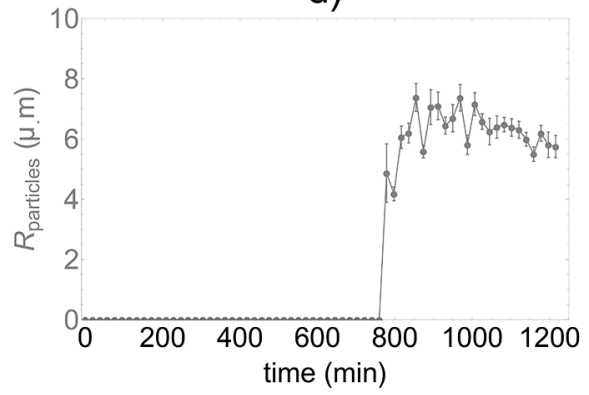

Figure 7. (a-c) Evolution with time of (a) $I_{\text {micelles }}(q=0)\left(\mathrm{cm}^{-1}\right)$, (b) the micelle radius $R_{\text {micelles }}(\mathrm{nm})$, and (c) the ellipticity of the micelles $\varepsilon$ extracted from the fitting of the SANS data measured previously at LOQ. Around $650 \mathrm{~min}$, a sudden increase in scale and ellipticity is observed, associated with the formation of a gel. (d) Particle radius measured in SESANS (Delft) over time. At 800 min, a signal of very large particles is observed and corresponds to macroscopic phase separation.
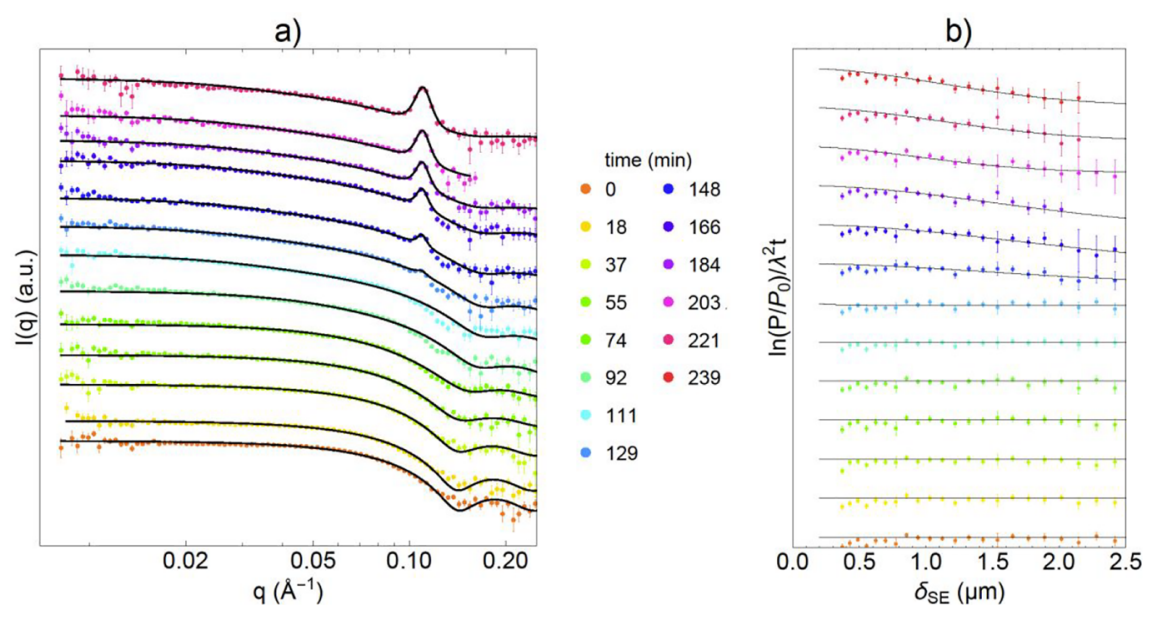

Figure 8. (a) $I(q)$ versus $q\left(\right.$ in $\left.\AA^{-1}\right)$ obtained from SANS measurements and (b) normalized neutron spin-echo signal $\frac{\ln \left(\frac{P}{P_{0}}\right)}{\lambda^{2} t}$ versus the spin-echo length $\delta_{\mathrm{SE}}($ in $\mu \mathrm{m})$ obtained from SEMSANS measurements for the kinetic runs using $\mathrm{C}_{16} \mathrm{EO}_{8}$ as surfactant with $r_{\mathrm{mol}}=7.21$. All patterns (a,b) were shifted for clarity (nonshifted SANS spectra can be found in Figure S8, SI). The color gives the time associated with each pattern. Black lines showing the fits of the SANS and SEMSANS data are presented according to the models given in SANS and SEMSANS Data Analysis.

of the system is triggered by the addition of the silica source, which rapidly hydrolyzes but slowly condenses in the acidic environment. This allows the incorporation of silica species within the micelles. Over time, incorporation of the silica species gradually elongates the micelles shape and the silica polymer grows in the solution. Finally, phase separation occurs, and mesostructured particles are formed in solution. Particles are formed containing micelles in an ordered mesophase, presumed to be a $2 \mathrm{D}$ hexagonal arrangement when $\mathrm{CTAB}$ is used as the templating surfactant, as can be observed by the concomitance of the emergence of a signal of particles in SEMSANS with the Bragg peak associated with the micelle organization in SANS. The fact that no large objects can be observed in SEMSANS prior to the emergence of the Bragg peak in SANS, coupled with the fact that micelles are noninteracting prior to the phase separation, suggests that upon precipitation micelles in the particles quickly rearrange into a mesophase with several domains but that the number of ordered domains increases with time due to further adsorption of silica enriched micelles, while the particle size shrinks a little due to the rearrangement of the micelles and continuing silica condensation. Indeed, after the formation of the particles, the signal of the remaining micelles in solution continues to decrease over time as they are added to the already formed 


\section{a)}

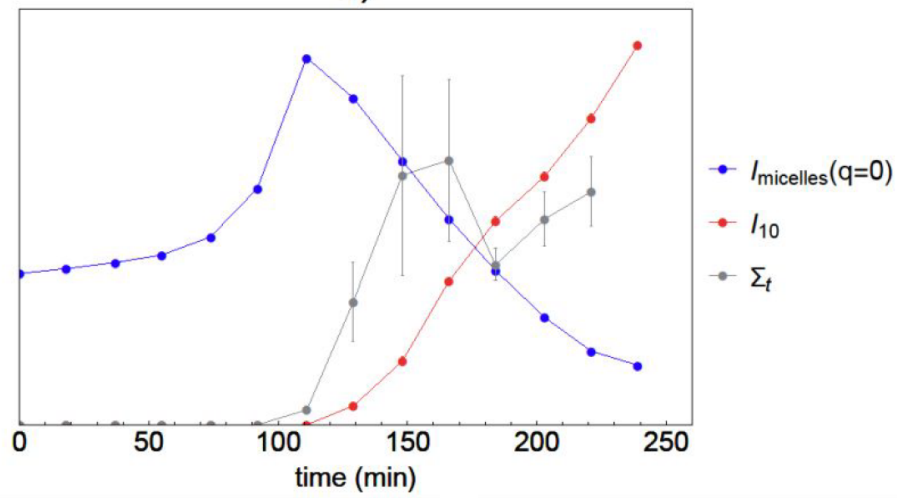

b)

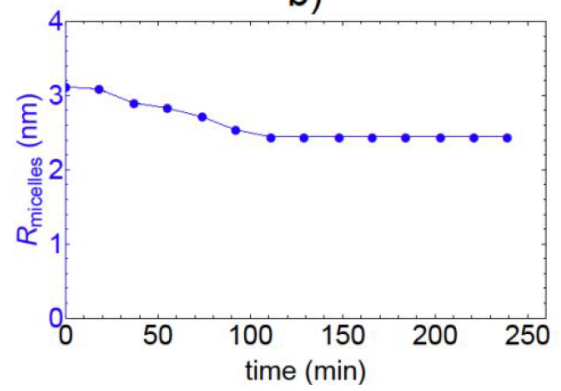

d)

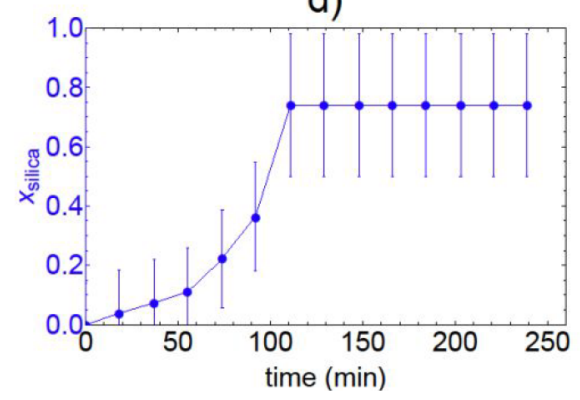

c)

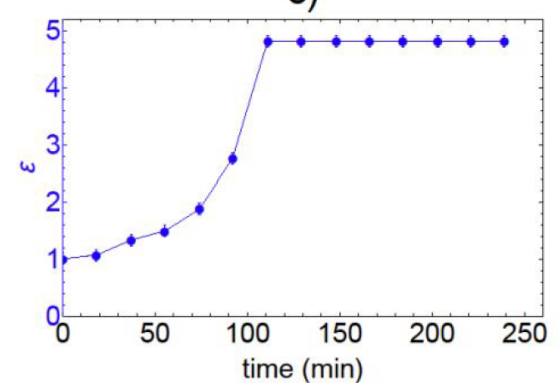

e)

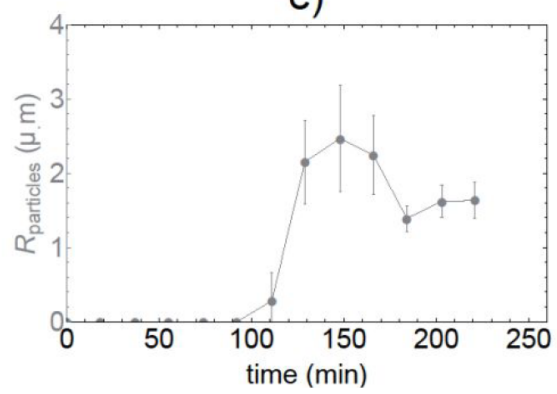

Figure 9. Evolution of different parameters extracted from fitting the SANS and SEMSANS data of the reaction in solution using $\mathrm{C}_{16} \mathrm{EO}_{8}$ at a ratio $r_{\text {mol }}=7.21$. (a) Comparison between $I_{\text {micelles }}(q=0)$ (blue), $I_{10}$ (red), and $\Sigma_{t}$ (gray) with time. Separated graphs with their associated scales can be found in Figure S9, SI. (Blue) (b) the micelle radius $R_{\text {micelles }}(\mathrm{nm})$, (c) the ellipticity of the micelles $\varepsilon$, and (d) $x_{\text {silica }}$ the amount of silica incorporated in the micelles obtained from fitting the SANS data. (Gray) (e) the radius $R_{\text {particles }}(\mu \mathrm{m})$ of micrometer-sized particles detected in SEMSANS. Other fitting parameters can be found in Figure S10, SI.

particles. A portion of these mesostructured particles are assumed to migrate to the interface to form the rough mesostructured silica film previously observed in GISAXS. This model of formation of mesostructured particles is valid for both $\mathrm{CTAB}$ and $\mathrm{C}_{16} \mathrm{EO}_{8}$. The ratio of silica source compared to surfactant influences the reaction rate or even disturbs this mechanism when too much silica is added, by competition between silica-surfactant and silica-silica interactions.

\section{ASSOCIATED CONTENT}

\section{SI Supporting Information}

The Supporting Information is available free of charge at https://pubs.acs.org/doi/10.1021/acsami.0c03287.

Additional information and figures (PDF)

\section{AUTHOR INFORMATION}

\section{Corresponding Author}

Julien Schmitt - Department of Chemistry, University of Bath, BA2 7AY Bath, United Kingdom; (1) orcid.org/0000-00023452-6655; Email: Julien.Schmitt@saint-gobain.com

\section{Authors}

Jan Joost Zeeuw - Department of Chemistry, University of Bath, BA2 7AY Bath, United Kingdom; Faculty of Applied Sciences, Delft University of Technology, 2629JB Delft, The Netherlands

Jeroen Plomp - Faculty of Applied Sciences, Delft University of Technology, 2629JB Delft, The Netherlands

Wim G. Bouwman - Faculty of Applied Sciences, Delft University of Technology, 2629JB Delft, The Netherlands

Adam L. Washington - ISIS Neutron and Muon Facility, Rutherford Appleton Laboratory, Oxfordshire OX11 OQX, United Kingdom 
Robert M. Dalgliesh - ISIS Neutron and Muon Facility, Rutherford Appleton Laboratory, Oxfordshire OX11 OQX,

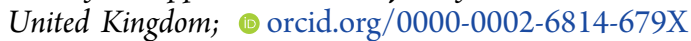

Chris P. Duif - Faculty of Applied Sciences, Delft University of Technology, 2629JB Delft, The Netherlands

Michel A. Thijs - Faculty of Applied Sciences, Delft University of Technology, 2629JB Delft, The Netherlands

Fankang Li - Neutron Technologies Division, Oak Ridge National Laboratory, Oak Ridge, Tennessee 37830, United States

Roger Pynn - Neutron Technologies Division, Oak Ridge National Laboratory, Oak Ridge, Tennessee 37830, United States; Centre for Exploration of Energy and Matter, Indiana University, Bloomington, Indiana 47408, United States

Steven R. Parnell - Faculty of Applied Sciences, Delft University of Technology, 2629JB Delft, The Netherlands

Karen J. Edler - Department of Chemistry, University of Bath, BA2 7AY Bath, United Kingdom; — orcid.org/0000-00015822-0127

Complete contact information is available at: https://pubs.acs.org/10.1021/acsami.0c03287

\section{Notes}

The authors declare no competing financial interest.

The data supporting this paper are openly available from the ISIS Neutron and Muon Source Data Journal at https://data. isis.stfc.ac.uk/doi/STUDY/103200345/.

\section{ACKNOWLEDGMENTS}

Experiments at the ISIS Pulsed Neutron and Muon Source were supported by a beamtime allocation for Larmor from the Science and Technology Facilities Council under proposal number RB1710181. Jan S. Pedersen is warmly thanked for designing the homemade Fortran software used to fit the SANS data. Part of this research was funded by a NWO groot (Grant LARMOR 721.012.102). F. Li would like to acknowledge the support from Oak Ridge National Laboratory, managed by UT-Battelle, LLC, for the U. S. Department of Energy. R. Pynn acknowledges partial support from the US Department of Commerce through cooperative agreement number 70NANB15H259. The authors warmly thank Ernst van der Wal for the design of the front cover associated to this article

\section{REFERENCES}

(1) Kresge, C. T.; Leonowicz, M. E.; Roth, W. J.; Vartuli, J. C.; Beck, J. S. Ordered Mesoporous Molecular Sieves Synthesised By A Liquid Crystal Template Mechanism. Nature 1992, 359, 710-712.

(2) Zhao, D.; Huo, Q.; Feng, J.; Chmelka, B. F.; Stucky, G. D. Nonionic Triblock And Star Diblock Copolymer And Oligomeric Surfactant Syntheses Of Highly Ordered, Hydrothermally Stable, Mesoporous Silica Structures. J. Am. Chem. Soc. 1998, 120, 60246036.

(3) Beck, J. S.; Vartuli, J. C.; Roth, W. J.; Leonowicz, M. E.; Kresge, C. T.; Schmitt, K. D.; Chu, C. T.-W.; Olson, D. H.; Sheppard, E. W.; Mccullen, S. B.; Higgins, J. B.; Schlenker, J. L. A New Family Of Mesoporous Molecular Sieves Prepared With Liquid Crystal Templates. J. Am. Chem. Soc. 1992, 114, 10834-10843.

(4) Melosh, N. A.; Lipic, P.; Bates, F. S.; Wudl, F.; Stucky, G. D.; Fredrickson, G. H.; Chmelka, B. F. Molecular And Mesoscopic Structures Of Transparent Block Copolymer-Silica Monoliths. Macromolecules 1999, 32, 4332-4342.
(5) Melosh, N. A.; Davidson, P.; Chmelka, B. F. Monolithic Mesophase Silica With Large Ordering Domains. J. Am. Chem. Soc. 2000, 122, 823-829.

(6) Grosso, D.; Cagnol, F.; Soler-Illia, G. J. d. A. A.; Crepaldi, E. L.; Amenitsch, H.; Brunet-Bruneau, A.; Bourgeois, A.; Sanchez, C. Fundamentals Of Mesostructuring Through Evaporation-Induced Self-Assembly. Adv. Funct. Mater. 2004, 14, 309-322.

(7) Yang, H.; Kuperman, A.; Coombs, N.; Mamiche-Afara, S.; Ozin, G. A. Synthesis Of Oriented Films Of Mesoporous Silica On Mica. Nature 1996, 379, 703-705.

(8) Grosso, D.; Balkenende, A. R.; Albouy, P. A.; Lavergne, M.; Mazerolles, L.; Babonneau, F. Highly Oriented 3D-Hexagonal Silica Thin Films Produced With Cetyltrimethylammonium Bromide. J. Mater. Chem. 2000, 10, 2085-2089.

(9) Edler, K. J.; Yang, B. Formation Of Mesostructured Thin Films At The Air-Liquid Interface. Chem. Soc. Rev. 2013, 42, 3765-3776.

(10) Yang, H.; Coombs, N.; Sokolov, I.; Ozin, G. A. Free Standing And Oriented Mesoporous Silica Films Grown At The Air-Water Interface. Nature 1996, 381, 589-592.

(11) Aksay, I. A.; Trau, M.; Manne, S.; Honma, I.; Yao, N.; Zhou, L.; Fenter, P.; Eisenberger, P. M.; Gruner, S. M. Biomimetic Pathways For Assembling Inorganic Thin Films. Science 1996, 273, 892-898.

(12) Clark Wooten, M. K.; Koganti, V. R.; Zhou, S.; Rankin, S. E.; Knutson, B. L. Synthesis And Nanofiltration Membrane Performance Of Oriented Mesoporous Silica Thin Films On Macroporous Supports. ACS Appl. Mater. Interfaces 2016, 8, 21806-21815.

(13) Rafti, M.; Brunsen, A.; Fuertes, M. C.; Azzaroni, O.; Soler-Illia, G. J. A. A. Heterogeneous Catalytic Activity Of Platinum Nanoparticles Hosted In Mesoporous Silica Thin Films Modified With Polyelectrolyte Brushes. ACS Appl. Mater. Interfaces 2013, 5, 88338840.

(14) Grosso, D.; Soler-Illia, G. J. D. A.; Babonneau, F.; Sanchez, C.; Albouy, P. A.; Brunet-Bruneau, A.; Balkenende, A. R. Highly Organized Mesoporous Titania Thin Films Showing Mono-Oriented 2D Hexagonal Channels. Adv. Mater. 2001, 13, 1085-1090.

(15) Ji, H. J.; Liu, X. H.; Wang, X. Zro2-Sno2 Nanocomposite Film Containing Superlattice Ribbons. J. Mol. Struct. 2010, 975, 47-52.

(16) Karlsson, J.; Atefyekta, S.; Andersson, M. Controlling Drug Delivery Kinetics From Mesoporous Titania Thin Films By Pore Size And Surface Energy. Int. J. Nanomed. 2015, 10, 4425-4436.

(17) Bouwman, W. G.; Duif, C. P.; Plomp, J.; Wiedenmann, A.; Gähler, R. Combined SANS-SESANS, From $1 \mathrm{~nm}$ To $0.1 \mathrm{~mm}$ In One Instrument. Phys. B 2011, 406, 2357-2360.

(18) Kusmin, A.; Bouwman, W. G.; Van Well, A. A.; Pappas, C. Feasibility And Applications Of The Spin-Echo Modulation Option For A Small-Angle Neutron Scattering Instrument At The European Spallation Source. Nucl. Instrum. Methods Phys. Res., Sect. A 2017, 856, 119-132.

(19) Li, F.; Parnell, S. R.; Dalgliesh, R.; Washington, A.; Plomp, J.; Pynn, R. Data Correction Of Intensity Modulated Small-Angle Scattering. Sci. Rep. 2019, 9, 8563.

(20) Brennan, T.; Hughes, A. V.; Roser, S. J.; Mann, S.; Edler, K. J. Concentration-Dependent Formation Mechanisms In Mesophase Silica-Surfactant Films. Langmuir 2002, 18, 9838-9844.

(21) Fernandez-Martin, C.; Edler, K. J.; Roser, S. J. Evolution Of Non-Ionic Surfactant Templated Silicate Films At The Air-Liquid Interface. J. Mater. Chem. 2008, 18, 1222-1231.

(22) Gähler, R. A Certain Class Of Beam Modulation Techniques And Its Potential Applications. In PNCMI Polarised Neutron School; Berlin Germany, 2006.

(23) Li, F.; Parnell, S. R.; Hamilton, W. A.; Maranville, B. B.; Wang, T.; Semerad, R.; Baxter, D. V.; Cremer, J. T.; Pynn, R. Superconducting Magnetic Wollaston Prism For Neutron Spin Encoding. Rev. Sci. Instrum. 2014, 85, No. 053303.

(24) Li, F.; Parnell, S. R.; Wang, T.; Baxter, D. V.; Pynn, R. Magnetic Field Optimization And Design Of A Superconducting Neutron Wollaston Prism. J. Phys.: Conf. Ser. 2016, 711, No. 012015. 
(25) Andersson, R.; Van Heijkamp, L. F.; De Schepper, I. M.; Bouwman, W. G. Analysis Of Spin-Echo Small-Angle Neutron Scattering Measurements. J. Appl. Crystallogr. 2008, 41, 868-885.

(26) Parnell, S. R.; Woolley, E. B.; Boag, S.; Frost, C. D. Digital Pulsed NMR Spectrometer For Nuclear Spin-Polarized 3He And Other Hyperpolarized Gases. Meas. Sci. Technol. 2008, 19, No. 045601.

(27) Parnell, S. R.; Babcock, E.; Nünighoff, K.; Skoda, M. W. A.; Boag, S.; Masalovich, S.; Chen, W. C.; Georgii, R.; Wild, J. M.; Frost, C. D. Study Of Spin-Exchange Optically Pumped 3He Cells With High Polarisation And Long Lifetimes. Nucl. Instrum. Methods Phys. Res., Sect. A 2009, 598, 774-778.

(28) Bouwman, W. G.; Duif, C. P.; Gähler, R. Spatial Modulation Of A Neutron Beam By Larmor Precession. Phys. B 2009, 404, 25852589.

(29) Li, F.; Parnell, S. R.; Bai, H.; Yang, W.; Hamilton, W. A.; Maranville, B. B.; Ashkar, R.; Baxter, D. V.; Cremer, J. T.; Pynn, R. Spin Echo Modulated Small-Angle Neutron Scattering Using Superconducting Magnetic Wollaston Prisms. J. Appl. Crystallogr. 2016, 49, 55-63.

(30) Boag, S.; Parnell, S. R.; Frost, C. D.; Andersen, K. H.; Babcock, E. Demonstration Of The Use Of Polarised $3 \mathrm{He}$ As A Broadband Polariser On A Pulsed Time-Of-Flight Neutron Source. Phys. B 2007, 397, 179-181.

(31) Boag, S.; Babcock, E.; Andersen, K. H.; Becker, M.; Charlton, T. R.; Chen, W. C.; Dalgliesh, R. M.; Elmore, S. D.; Frost, C. D.; Gentile, T. R.; Lopez Anton, R.; Parnell, S. R.; Petoukhov, A. K.; Skoda, M. W. A.; Soldner, T. In Situ SEOP Polarised 3He Neutron Spin Filter For Incident Beam Polarisation And Polarisation Analysis On Neutron Scattering Instruments. Phys. B 2009, 404, 2659-2662.

(32) Rekveldt, M. T.; Plomp, J.; Bouwman, W. G.; Kraan, W. H.; Grigoriev, S.; Blaauw, M. Spin-Echo Small-Angle Neutron Scattering In Delft. Rev. Sci. Instrum. 2005, 76, No. 033901.

(33) Manet, S.; Schmitt, J.; Impéror-Clerc, M.; Zholobenko, V.; Durand, D.; Oliveira, C. L. P.; Pedersen, J. S.; Gervais, C.; Baccile, N.; Babonneau, F.; Grillo, I.; Meneau, F.; Rochas, C. Kinetics Of The Formation Of 2D-Hexagonal Silica Nanostructured Materials By Nonionic Block Copolymer Templating In Solution. J. Phys. Chem. B 2011, 115, 11330-11344.

(34) Schmitt, J.; Kjellman, T.; Kwaśniewski, P.; Meneau, F.; Pedersen, J. S.; Edler, K. J.; Rennie, A. R.; Alfredsson, V.; ImpérorClerc, M. Outset Of The Morphology Of Nanostructured Silica Particles During Nucleation Followed By Ultrasmall-Angle X-Ray Scattering. Langmuir 2016, 32, 5162-5172.

(35) Pedersen, J. S. Analysis Of Small-Angle Scattering Data From Colloids And Polymer Solutions: Modeling And Least Squares Fitting. Adv. Colloid Interface Sci. 1997, 70, 171-210.

(36) Brennan, T.; Roser, S. J.; Mann, S.; Edler, K. J. The Structural Evolution Of Surfactant Silica Film Forming Solutions, Investigated Using Small-Angle Neutron Scattering. Chem. Mater. 2002, 14, 42924299.

(37) Sundblom, A.; Oliveira, C. L. P.; Palmqvist, A. E. C.; Pedersen, J. S. Modeling In Situ Small-Angle X-Ray Scattering Measurements Following The Formation Of Mesostructured Silica. J. Phys. Chem. C 2009, 113, 7706-7713.

(38) Sundblom, A.; Oliveira, C. L. P.; Pedersen, J. S.; Palmqvist, A. E. C. On The Formation Mechanism Of Pluronic-Templated Mesostructured Silica. J. Phys. Chem. C 2010, 114, 3483-3492.

(39) Edler, K. J.; Goldar, A.; Hughes, A. V.; Roser, S. J.; Mann, S. Structural Studies On Surfactant-Templated Silica Films Grown At The Air/Water Interface. Microporous Mesoporous Mater. 2001, 4445, 661-670.

(40) Edler, K. J.; Brennan, T.; Roser, S. J.; Mann, S.; Richardson, R. M. Formation Of CTAB-Templated Mesophase Silicate Films From Acidic Solution. Microporous Mesoporous Mater. 2003, 62, 165-175.

(41) Strobl, M. General Solution For Quantitative Dark-Field Contrast Imaging With Grating Interferometers. Sci. Rep. 2015, 4, 7243.
(42) Richman, E. K.; Brezesinski, T.; Tolbert, S. H. Vertically Oriented Hexagonal Mesoporous Films Formed Through Nanometre-Scale Epitaxy. Nat. Mater. 2008, 7, 712-717.

(43) Wang, Y. L.; Kimura, K.; Dubin, P. L.; Jaeger, W. Polyelectrolyte-Micelle Coacervation: Effects Of Micelle Surface Charge Density, Polymer Molecular Weight, And Polymer/Surfactant Ratio. Macromolecules 2000, 33, 3324-3331.

(44) Chan, H. B. S.; Budd, P. M.; Naylor, T. D. Control Of Mesostructured Silica Particle Morphology. J. Mater. Chem. 2001, 11, 951-957. 